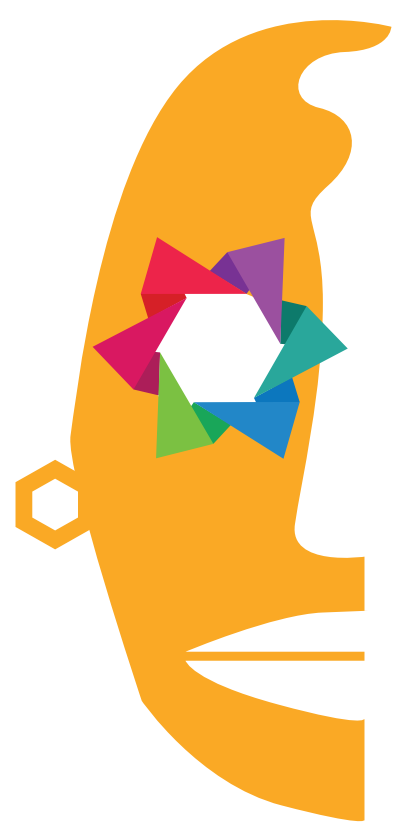

Julia M. Medina

Universidad de San Diego Estados Unidos

\title{
Rubén Darío. Despedidas de la Tierra ${ }^{1}$
}

\section{Resumen}

Este trabajo aborda algunos de los últimos registros de Rubén Darío, para señalar cómo su obra socava la modernidad latinoamericana, más allá de cómo se ha entendido y se ha practicado tradicionalmente, incluso por él mismo, suturando mundos que seguimos sin consolidar.

Palabras clave: modernidad, modernismo, eco-crítica, textos liminares, colonialidad del saber

\begin{abstract}
In looking at different genres, this article addresses some of Rubén Darío's lasts texts, to illustrate how his work disavows modernity as understood and practiced traditionally, even by him; thereby suturing unconsolidated spheres of a world still fragmented.
\end{abstract}

Keywords: modernity, modernism, eco-criticism, textual liminality, coloniality of knowledge

1 Una versión preliminar de este trabajo, bajo el título "Modernismo nómada y últimas gestas de Rubén Darío", se presentó en el congreso La sutura de los mundos, llevado a cabo en Buenos Aires del 7 al 10 de marzo de 2016 y fue entregado para su publicación en Actas. Otra versión reducida y traducida al inglés por Jason Weiss, titulada "Rubén Darío. Eartlhy Farewells" será publicada en Review: Literature and Arts of the Americas No. 97, otoño 2018. 
A cien años de su partida, consecuente con la lógica bio-política ${ }^{2}$ del linaje hereditario, el legado de Rubén Darío sigue sujeto a enmarques tradicionales de lectura, producto en parte de la parcelación de saberes y del espacio terrenal que marca nuestra época. La prolífica extensión de su obra, celebrada sobre todo por su poesía, incluye prosa y narrativa, complicando su acercamiento crítico. Igualmente, el carácter transnacional de su producción y de su trayectoria bio-geo-gráfica dificulta la centralización de su obra, por lo que se trata de un archivo orgánico en constante devenir. Como príncipe de las letras hispanas, su nobleza fue simbólica, por tanto, su obra y figura siguen a merced de maniobras tangibles y figuradas, políticas y culturales que distorsionan el material humano y simbólico del autor ${ }^{3}$.

Considerando el hito del centenario como corte conmemorativo, aquí me interesa indagar en cómo concluye el poeta su obra escrita en distintos registros. Es decir, indagar cómo él cierra su repertorio y se despide de sus lectores en textos que incluyen la escritura epistolar, la poesía, la crónica, y la narrativa; teniendo de trasfondo el registro autobiográfico que anticipa la conclusión de su vida pública. Interesa incluir La vida de Rubén Darío escrita por él mismo (1912) dentro de estas últimas gestas escriturales porque simbólicamente da por terminada su vida profesional cuatro años antes de su muerte 4 . Este precipitado cierre se produce gracias a una solicitud de Caras y Caretas durante un momento de necesidad económica del poeta. Además del individualismo artístico y el liberalismo, entran en juego en este espacio cortes personales-profesionales, que atraviesan y le dan forma y cierre a lo est/ético y político. Dentro de la heterogeneidad de este texto, Delgado Aburto (2012) atina al argumentar que "[...] la forma autobiográfica parece reconocerse en actividades paradójicas como las de la crónica necrológica y la comicidad del payaso" (p. 50). Apunto a esta dialéctica en el tono de la autobiografía porque esta se observa en las distintas despedidas, con la excepción del poema.

2 Foucault (1990) explica que el bio-poder, esquema general de la bio-política, se refiere a las formas históricamente arraigadas en la institucionalización del control social para disciplinar cuerpos, tanto individuales como colectivos. El control sobre la sexualidad y los cuerpos, ejemplifica cómo se manifiesta la bio-política a partir del siglo XVIII. Hoy se habla a formas de biopolítica según distintos contextos que corresponde a avances tecnológicos, demográficos y demás.

3 Por ejemplo, referirse al estudio de Blandón, 2011, pp. 104-126. Desde otros registros, la presente autora ha hecho referencia a esto en Medina, 2010, pp. 82-103, donde se aborda las últimas imágenes fotográficas que se hicieron del poeta, del último prólogo que escribió a su propia obra, y también su presentación del poema "Pax" en Nueva York como último acto público. Estos ensayos forman parte de la colección editada por Browitt, J. \& Mackenbach, W. 2010. Rubén Dario: cosmopolita arraigado. Nicaragua: Instituto de Historia de Nicaragua y de Centro América.

4 Desarrollando lo sugerido por Rama, Delgado Aburto (2005), señala que la autobiografía es un texto que "responde a un específico tipo de interpelación, en la que el liberalismo y el individualismo artístico articulan un espacio discursivamente conflictivo" (artículo cibernético). Delgado Aburto desarrolla otro análisis de la misma en su libro Excéntricos y periféricos: escritura autobiográfica y modernidad en Centroamérica (2012), Pittsburgh: Universidad de Pittsburgh. 
Además de insistir en la complejidad de su producción, este corte de lectura de los últimos escritos de Darío pone en evidencia la tragedia y la tiranía que marcan su legado. Puesto a que su fallecimiento no fue un hecho repentino, desde el punto de vista de la tragedia, este vistazo de sus últimas expresiones textuales registra el umbral ontológico del autor, el cual va a contrapelo de los modelos ideológicos modernistas que lo sustentaban y a los que se adscribía. Se podría decir que las inquietudes que presenta el autor en estos escritos, tanto en forma como en contenido, más que reproducir un cosmopolitismo tradicional centrado en las ciudades, anticipan una subjetividad nómada según la propuesta de Braidotti $(2011)^{5}$. Desde su perspectiva periférica y siempre nómade (literal y figurado), los últimos textos de Darío problematizan las transformaciones culturales y sociales que marcaron el cruce finisecular. Se trata del nomadismo no como metáfora, sino como una "[...] critical tool to account for the materiality embedded and embodied locations and power relations" (Braidotti, 2011, p. 12). Si la figuración nómada cuenta con una fuerza imaginativa en sintonía con las estructuras energizadas y transnacionales de nuestra situación histórica (Braidotti, 2011), el escritor responde a su situación histórica a través de las tecnologías como la imprenta, los transatlánticos, los barcos y los rieles que materializan esos desplazamientos físicos, afectivos, genéricos, y estéticos de su época.

En cuanto a la tiranía expuesta en los últimos escritos de Darío, sobresale su anticipación sobre los procesos del bio-poder, según lo articularía después Foucault $(1976)^{6}$, quien indica que el siglo XIX marca la transición de las operaciones del poder de los usos simbólicos de la sangre, al análisis de la sexualidad (1990, p. 148). Consecuente con la lógica bio-política ${ }^{7}$ del linaje hereditario, como soberano de la lengua, Darío estuvo sujeto a distintos tipos violencia en su vida privada y pública ya desde su infancia. Estos escritos, al igual que su legado físico, textual, simbólico y materia, registran lo dicho. Por ejemplo, en referencia a sus desplazamientos biogeográficos, a sus emparejamientos, a sus hijos, a su alcoholismo, a las circunstancias trágicas en torno a su agonía, y posteriormente a sus

5 Además de implicar una ambigüedad originaria en cuanto a procedencia o a identidad de género, Braidotti (2011) explica que subjetividad nómada es una "herramienta analítica y como proyecto creativo dirigido a cualificar el cambio de conciencia que corresponde al espíritu de nuestra época” (p. 11). Sorteando caer en anacronismos, en este caso, Darío encarna una subjetividad nómada desde su época.

6 Según este planteamiento, el bio-poder es un esquema general de la bio-política y se refiere a las formas históricamente arraigadas en la institucionalización del control social para disciplinar cuerpos, tanto individuales como colectivos. El control sobre la sexualidad y los cuerpos ejemplifica cómo se manifiesta la bio-política a partir del siglo XVIII. Cf. Foucault, 1990, pp. 135-159.

7 Según Foucault (2010) en la época feudal el bio-poder se presenta a través de la función simbólica y el valor de la sangre, como medida de sacrificio, linaje, alianzas, descendencia y demás. Mientras que en el siglo $\mathrm{XX}$ se torna a los usos de la sexualidad como asunto político, embrollado a la disciplina del cuerpo y a la vida de la especie. 
restos $^{8}$, donde se cristalizan formas del bio-poder que pasa a ser una tatanopolítica individual, en el caso de su figura pública. Para indagar en estos espacios liminares entre lo público y lo privado, lo literario y lo funcional, y así problematizar las divisiones disciplinarias que limitan un acercamiento actual a su obra, empezaremos con un vistazo a su última misiva.

Dictada en el lecho de su muerte en enero de $1916^{9}$, y dirigida al director de $L a$ Nación Emilio Mitre y Vedia, el final de esta supuesta última misiva ejemplifica esta preocupación por lo material, tanto biológico como económico, y por los bienes simbólicos:

[a] usted le pido por mi hijo, ahora solo, y a quien ruego tener por único heredero de mis bienes. Me despido de usted con el agradecimiento que le debo por sus cuidados. He servido a La Nación con todo mi pensamiento y a usted con mi respeto más devoto. (Darío, 2000, p. 404, cursivas nuestras)

Sin ningún otro cierre más que su nombre, Darío concluye su repertorio epistolar dejando clara su precaria situación. Este documento despliega sus desarraigues prácticos, y las cartografías desiguales de poder dentro de las que tuvo que navegar. Así mismo, sirviéndole "con todo su pensamiento" (Darío, 2000, p. 404), reafirma la distancia profesional entre su función periodística y su poesía, la cual queda elípticamente protegida del mercantilismo implicado.

Conjugado a su preocupación por el hijo, en la misma misiva deja testamento, tanto retórico como literal, de otros lazos afectivos "i[1]loro pensar que nunca más volveré a ver tierra argentina!" (2000, p. 404). Además de sugerir una visión planetaria, la palabra "tierra" apunta su nostalgia al suelo, al campo, ya sea en la llanura o en la pampa, lejos de la urbe. Así, su lamento desde Nicaragua por no volver a Argentina, y por su hijo en España, resume escuetamente el desarraigo afectivo y efectivo de su condición nómada y transeúnte. Siguiendo las ideas del nomadismo, utilizamos el término trashumante para inducir el cuestionamiento de las configuraciones urbanas en favor de espacios rurales, campestres o "abiertos". Sugerente también que su sentimentalismo convoque un retorno a la tierra del país, no necesariamente a la ciudad de Buenos Aires, siempre insistiendo en una ordenación nacional. En estos registros

8 Contreras (2012) explica en su biografía de Darío: "Se originó un altercado violento, que dio por resultado que el codiciado cerebro fuera conducido a la Dirección de Policía para esperar la decisión del Gobierno ¿Pero qué sentimientos movían a estas personas que osaban poner en prisión la parte más noble del más grande poeta de América?” (p. 178). El positivismo científico, conjugado a los supuestos derechos de propiedad, incitan la disputa por el material encefálico del escritor.

9 En Arellano (comp.). (2000), la supuesta última carta dirigida desde Guatemala a su compañera de vida, Francisca Sánchez, tiene fecha del 12 de agosto de 1915. En ella hace referencia despectiva de su primer hijo con la esposa Rafaela Contreras: “[e]stuvo aquí el Rubén Trigueros. Se fue. Es un sinvergüenza” (Arellano [comp.], 2000, p. 402). Menciono esta referencia para señalar la cuestión de la bio-política y el des/ afecto. 
textuales que le dan un cierre a su vida, queda en evidencia esta subjetividad nómada $\mathrm{y}$ trashumante que privilegia la idea abstracta de la nación ${ }^{10} \mathrm{y}$ sus espacios abiertos.

En contraste al tono desamparado en el fin de esta misiva, esta empieza con un tono lúdico que insiste en su preferencia campestre: "en mis deseos está el mejorarme un poco para irme al campo, gozar de la soledad, de buena mesa y montar un burro como Sileno para caminar al sol, y sentir el soplo libre del monte" (2000, p. 404, cursivas nuestras). A pesar de haber nacido y haber pasado los primeros años de su vida en el campo, su mundo personal tanto como vocacional lo secuestran a las "ciudades letradas" que debía habitar y condecorar como su máximo exponente ${ }^{11}$. Recordemos que León y cualquier otra ciudad de Nicaragua en el siglo XIX eran precarios puntos urbanos entorno a una exuberante naturaleza. Fuera de cualquier pose romántica, su vida y obra están condicionadas por esta tensión entre la configuración urbana y una preferencia o nostalgia personal por el campo, o "la naturaleza", como concepto y realidad que entra en conflicto con su profesión ${ }^{12}$. Entre paréntesis cabe notar que como concepto "la naturaleza" vacía el referente de su complejidad denotativa, como así también se alinea a las ideologías extractivas que sustentan el liberalismo como practica y condición de la supuesta modernidad ${ }^{13}$. Entonces, la condición errante de Darío, que empezó desde su infancia en el traslado abrupto del campo a la ciudad, incide en su trayectoria vocacional, permitiéndole apuntar a otras configuraciones de estética y de pertenencia, en parte desapercibidas o descartadas por su alcance, donde sortea y neutraliza estos desplazamientos.

Reparemos en las primeras páginas de la autobiografía, donde registra que sus primeros recuerdos son en el campo, presentados como eventos cerrados, distanciados de su trayecto profesional y de su presente enunciativo. Después de explicar su genealogía y su nombre, el primer recuerdo de Darío (1991) es

el de un país montañoso [...] en tierras de Honduras, por la frontera nicaragüense; una señora delgada, de vivos y brillantes ojos negros-¿negros?... no lo puedo afirmar seguramente..., mas así los veo ahora en mi vago y como ensoñado recuerdo. (p. 8)

10 No obstante, su cuestionamiento del paradigma nacional se presenta, por ejemplo, cuando sirvió de editor para el La Unión Centroamericana en 1884. En 1889 también difunde su causa unionista al emitir un folleto titulado La Unión, como órgano de la unificación ístmica. Ese año se acordó un Pacto de Unión Centroamericana en El Salvador. La postura unionista de este documento lo comenta la presente autora en Medina, 2005, pp. 133-136.

11 Sin suponer discutir esta sensibilidad psicológica, Delgado Aburto (2012), nos señala que al final de su Autobiografía, Darío (2012) privilegia la isla sobre la metrópolis: "[e]fectivamente, Mallorca es presentada, en oposición a París, como lugar cualitativamente superior para la búsqueda del ensueño y la enunciación de sí. Aunque sin dejar de notar su relación con Barcelona, y la industria editorial” (pp. 40-42). Así, vemos esta tensión entre su preferencia campestre y la urbe que sustenta su vocación/producción.

12 Según Rama (1985) para el poeta la naturaleza se trata sólo de un "diagrama intelectual” (p. 109). Siguiendo estos términos, aquí se propondría más bien que constituye el diagrama afectivo o vital del poeta.

13 Aquí se hace referencia a Latour, 2013, p. 55; y Morton, 2007, pp. 14-26. 
En la incertidumbre del recuerdo en el campo se presenta un retrato de su madre: "[...] blanca, de tupidos cabellos oscuros, alerta risueña, bella. Esa era mi madre. La acompañaba una criada india" en la casa primitiva "sin ladrillos, en pleno campo" (1991, p. 8). El contraste entre la blanca madre y la criada india en ese espacio doméstico, constata las simetrías étnicas, sociales e históricas de su contexto y del lugar que él ocupa dentro de ese paradigma. En este entorno silvestre, jerarquizado y maternal, se incluye el cuadro travieso del niño que se pierde en el monte y es encontrado luego "debajo de las ubres de una vaca" (1991, p. 8). Así se despuntan, por un lado, la frontera del abandono, la frontera nacional, la frontera entre lo humano y lo animal; y por otro, el olvido y el recuerdo, el dolor y el placer de la nostalgia, lo artesanal y la tecnología: "Se me sacó de mi bucólico refugio, se me dio unas cuantas nalgadas y aquí mi recuerdo de esa edad desaparece como una vista de cinematógrafo" (1991, p. 8, cursivas nuestras). Se le saca de ese refugio inmediato y entra a formar parte de una configuración urbana, pese a sus lazos afectivos, lejos de las vacas y de su madre ${ }^{14}$. Las nuevas tecnologías se incorporan al imaginario del recuerdo para moldear la memoria dislocada que constituye su nomadismo modernista.

Consistente con el origen de la eco-crítica como marco teórico, la academia anglo-parlante ha reconocido aportes eco-críticos de Darío, mientras que la hispano-parlante lo ha considerado como una cuestión de sensibilidad psicológica, o como algo decorativo en su obra. Por ejemplo, White (2011) propone que el poeta es precursor del "eco-cosmopolitismo" (pp. 85-95) 15 y que nos presenta "formas más responsables de vivir en la tierra", según su ensayo en World Literature Today (2011, mi traducción). Por su parte, DeVerties (2013) explica que el "arte por el arte" (p. 23), como lema y práctica dariana, se manifiesta también en su percepción de la naturaleza por la naturaleza, a diferencia de sus homólogos anglosajones que insistían en esta como medio de desarrollo económico. En el esmero por creer y sentir la modernidad que Darío representa, el componente rural en su obra no ha sido lo suficientemente abordado desde el contexto hispano. Este tipo de menosprecio se inmiscuye en las prácticas políticas de desarrollo, cuyas repercusiones en el siglo XXI apuntan a uno de los temas vitales de nuestra época.

14 Sin pretender discutir esta sensibilidad psicológica, Delgado Aburto (2012) también nos señala que al final de su Autobiografía (1913), Darío inhabilita la ciudad de París para privilegiar el ensueño de la isla de Mallorca: "Efectivamente, Mallorca es presentada, en oposición a París, como lugar cualitativamente superior para la búsqueda del ensueño y la enunciación de sí. Aunque sin dejar de notar su relación con Barcelona, y la industria editorial" (pp. 40, 41-24). Así, vemos la tensión que venimos comentando entre su preferencia campestre y la urbe que sustenta su vocación/producción.

15 Se trata de un término desarrollado por Ursula K. Heise, en su libro Sense of Place and Sense of Planet: The Environmental Imagination of the Global (2008). También referirse a White, 2011, pp. 55-65 y pp. 85-95. 
Más allá de ser un recurso estético en la obra de Darío, el desdén por la naturaleza dentro de la crítica hispana tradicional revela una racionalidad colonial ${ }^{16}$ que privilegia lo urbano y lo cosmopolita, es decir, resguardando definiciones decimonónicas de modernidad. En referencia a Darío, Browitt y Mackenbach (2010) cuestionan la rigidez del término para insistir que el cosmopolitismo "se puede concebir como una crítica no positivista [...], contra el mundo social cerrado y circunscrito por las naciones-estado" y que sería lo que hoy se consideraría $a$ queering of literatura (p. 6) ${ }^{17}$. La polémica en torno a unas cartas que Darío presuntamente escribió a Amado Nervo, registra la dificultad de leer su obra desde cualquier ángulo queer ${ }^{18}$. Siguiendo esta línea, se puede decir que Darío encarna una subjetividad y experiencia nómada tanto en el sentido literal de la palabra como en su alcance teórico, el cual insiste en que dichas figuraciones, además de sobrepasar la categorización binaria de género, suponen la negación de separar la razón de la imaginación (Braidotti, 2011, p. 18). El mapa epistémico, además del artístico y ontológico que traza Darío como profesional del lenguaje a lo largo de sus escritos, confirma lo dicho.

El cosmopolita necesita pasaporte(s) para ser ciudadano del mundo y privilegia el orden de la metrópolis, mientras que la figura nómada, trashumante prospera en espacios abiertos ${ }^{19}$. Sin importarle pasaportes Darío se buscaba en esos lugares, al margen la urbe y de los esquemas metropolitanos. Delgado Aburto (2009) menciona este desarraigo en sus lecturas de la autobiografía de Rubén Darío; explica que "el modernista se hizo un errabundo (factual o metafórico), y operó de manera audaz dentro de la modernidad" (p. 36) y que su "distanciamiento lírico a los espacios libres de la naturaleza (un motivo por entero literario) anida la creación de una escritura" (p. 42). Esa retirada a los espacios libres como (pre)condición de escritura y del ser, necesitan perfilarse dentro de una est/ética sustentada en una experiencia rural. Esto queda de manifiesto en las otras formas que cuajan sus últimas gestas.

16 Siguiendo la propuesta de Quijano y Blandón (2011) en Discursos transversales: la recepción de Rubén Dario en Nicaragua, hace referencia a la racionalidad colonial y colonialidad del poder que opera en (torno) a Darío (pp. 13, 22-23). Por su parte, Rama (1985) nos señala que Julio Saavedra primero “equipara el modernismo con el liberalismo, estableciendo un paralelismo estrecho entre las escuelas literarias y las orientaciones políticas" (pp. 30-31). Gutiérrez Girardot (1983), a su vez, explica que el modernismo es una expresión de la expansión del capitalismo; "la 'universalización' de la literatura que va pareja a la unificación del mundo" (p. 16).

17 Browitt y Mackenbach, 2010, pp. 1-16. A pie de página citan las definiciones de Sokofsky Sedgwick y las de Lorey y Plews (1993) para aclarar que queering "puede referirse a cualquier desestabilización de regímenes normativos y autoritarios" (2010, p. 15).

18 En referencia al artículo de Acereda, 2012, pp. 895-924. Este artículo se basa en unas cartas encontradas en el archivo de Arizona State University, cuya validez ha sido refutada por expertos nicaragüenses. La polémica sobre el lugar de estas misivas en el archivo de Rubén Darío sigue vigente.

19 Aquí cabe considerar la palabra "abierto" en su sentido literal, y también al alcance filosófico y ontológico que presenta Agamben, 2005, pp. 75-82. 
Pasando al registro lírico de su escritura, en su último poema póstumo "Triste, muy tristemente...", resume su sufrimiento ingénito a su condición de artista y humano:
Un día estaba yo triste, muy tristemente viendo cómo caía el agua de una fuente; era la noche dulce y argentina. Lloraba/ la noche. Suspiraba la noche. Sollozaba la noche. Y el crepúsculo en su suave amatista, diluía la lágrima de un misterioso artista.
$\mathrm{Y}$ ese artista era yo, misterioso y gimiente,
Que mezclaba mi alma al chorro de la fuente. (1985, p. 485)

Sin precisar la forma de esa fuente, sea natural o urbana, la sustancia acuífera se presenta como objeto y sujeto de la subjetividad humana del artista, como también la noche se presenta como ente cómplice de su tristeza. El encabalgamiento del tercer y cuarto verso suspende el referente del llanto y lo hace recaer en la voz poética. Por otra parte, el adjetivo "argentina" sirve como eje de sinestesia hacia un cambio musical en la lírica que personifica la tristeza nocturna que, también, deja sugerido vínculos afectivos ${ }^{20}$. En esta despedida evoca a su espacio añorado, trasfondo de un giro borgeano que presenta la desintegración del alma de un artista, mezclada con la fuente como última metáfora de su reencuentro con lo eterno. En este último poema, el apego a cualquier lazo material o externo se desvanece y queda en adjetivo que pudiera ser clave de algún lugar diluido.

La relación de Darío con Argentina rompe con los esquemas nacionales de pertenencia, y revela dinámicas asimétricas de interdependencia regional de producción cultural. Ya sabemos que las editoriales porteñas le permitieron una profesionalización periodística / artística a partir de 1892, cuando anuncia su incorporación oficial a La Nación como corresponsal hasta el fin de sus días (Zanetti, 2004). No está de más que esta iniciación emprendiera en el cuarto centenario de la conquista, para cuya ocasión publica una crónica titulada: "La exposición histórico-americana en Madrid. Arqueología Precolombina"21. En producción, en contenido y en la biogeografía se revela un nomadismo que opera, como lo indica el título de esta crónica, sobre una arqueología de saber y de poder en el mapa hispanohablante; invirtiendo el orden colonial establecido dentro del campo literario, y resaltando otro tipo de jerarquía letrada.

En contrapunto, la última crónica que publica Darío en La Nación, en agosto de 1915, se titula "Apuntaciones de hospital", donde torna a su experiencia propia de la biopolítica. En este texto se aglutinan el desplazamiento físico, temporal, genérico y epistémico que venimos comentando, a medida que relata su experiencia

20 Blandón, 2010, p. 111; nos recuerda que Rubén Darío quería que lo enterrasen en Buenos Aires.

21 Tomando la palabra para marcar la ocasión, el texto se publica el 28 de septiembre de 1892. 
convaleciente durante su gira pacifista por Nueva York. Plasmando su simultaneidad, la crónica se publica durante el invierno argentino, mientras Darío se encontraba ya en Guatemala como invitado de honor de Manuel Estrada Cabrera ${ }^{22}$. Siguiendo el tono lúdico de Sileno en el campo, aquí trasluce cierto esnobismo que sirve para entretener al lector dentro de su desgracia: "[e]1 French Hospital, sin duda por no perder su carácter latino, es bastante mediocre y anticuado. Casi nadie habla francés" (2013, p. 382). La burla contrasta con el desamparo de estar internado en el extranjero: "[e]l aislamiento, la casi destrucción de la personalidad, el sentirse solitario, abandonado, olvidado, ponen en el alma una inexplicable opresión de angustia y desesperanza, sobre todo, en un pueblo de seres distintos, de espíritu y mentalidad distintos" (2013, p. 383). Su otredad acentúa la desintegración de un "yo" que pone en evidencia su necesidad económica, y la experiencia humana en el contexto trashumante.

A través de la crónica, como forma intermediaria de la experiencia subjetiva, artística y objetiva, se anticipan las premisas foucauldianas en cuanto al sometimiento corporal clínico ${ }^{23}$. Además de haber experimentado la bio-política a nivel civil $/ 24$ vocacional, también la supo señalar en su práctica médica:

Elige un dedo, dos. Los trucida, los traspasa, los transverbera, armado de un punzón como para matar un cochinillo de Indias, o una rata de égout [albañal]. El sacrificador, que me ha dejado la mano adolorida, con unos tubos de cristal y goma en la boca recoge la sangre, la coloca en los cristales para el microscopio. 'Bonjour' y se va. (2013, p. 385)

Sin dejar de lado el toque lúdico, este reportaje de su vivencia personal presenta un comentario sobre la continuidad histórica de la violencia biopolítica mediante el sacrificador. Atravesado por la experiencia "moderna", el sacrificador, transformado en médico, se presta de tecnologías regulatorias que deshumanizan al escritor ${ }^{25}$.

22 No hago referencia al poema que se vio obligado a publicar en Guatemala a favor de Estrada porque el tema del patrocinio y la dependencia queda demasiado en evidencia. Por ejemplo: Contreras (2012) señala explícitamente "[...] temeroso de perder su favor [Manuel Estrada Cabrera], nuestro poeta cedió, al fin, y él, que sonreía de la 'propaganda minervina' compuso una oda 'Palas Athenea', para ser declamado en las famosas fiestas de minerva, Pero su enfermedad lo libró de la vergüenza de leer aquella obra arrancada de su miseria y de su falta de carácter" (p. 168).

23 Foucault (1990) vincula los temas de la salud a la vitalidad social que implica el poder sobre la sexualidad y a la sexualidad. En este sentido se cuaja en esta experiencia esa transición de la sangre a la sexualidad como valores del poder.

24 El sometimiento al matrimonio que experimentó Darío (1991) se presenta de forma velada en su autobiografía: "Es una página dolorosa de violencia y engaño, que ha impedido la formación de un hogar por más de veinte años; pero vive aún quien como yo ha sufrido las consecuencias de un familiar paso irreflexivo" (p. 68).

25 Esta crónica hace eco a una anterior suya titulada: "La enfermedad del diario" (1897), la cual comenta Zanetti (2013) por "alud[ir] al campo de lo corporal en relación con en el periodismo: ‘...-carne y sangre nuestra, obreros de esas usinas! - director, gerente, administrador, redactor, colaborador, reporter” (pie de página, pp. 7, 126). 
Siguiendo con el tema de los sacrificios, cierro con su última ficción, el cuento "Huitzilopoxtli", por haber sido la última en volver a publicarse cuando iba de paso a Nicaragua antes de $\operatorname{morir}^{26}$. Aunque su último cuento inédito fue "El Cuento de Martín Guerre: Leyenda Nicaragüense", publicado en La Nación en junio de 1914, sabemos que se trata de la adaptación de una historia conocida, que además de hacerle un guiñe a la ciudad letrada de su época, sugiere un comentario irónico sobre la recepción de sus propios vaivenes en el contexto local. No obstante, "Huitzilopoxtli" ${ }^{27}$ fue el último en (volver a) publicarse, y su segunda publicación aparece con el subtítulo de "leyenda mexicana", no atribuido al escritor $^{28}$. Esta modificación en el título recalca una autenticidad popular que lo distancia de la ficción y lo reinserta en el ámbito local, arqueológico y folklórico. A pesar de demarcar fronteras epistémicas con el subtítulo, la reproducción del cuento, su temática y sus personajes presentan un despliegue transnacional que insiste en su subjetividad trashumante y nómada.

Además de ser uno de los primeros registros ficticios sobre la Revolución Mexica$\mathrm{na}^{29}$, la re-publicación del cuento en el contexto centroamericano le brinda cierta circularidad a la producción de crónicas, en cara a su primera entrega a La Nación, antes referida. Darío empieza haciendo reportajes para Escribir, y termina escribiendo para reportar. En la ficción, la arqueología y el imaginario precolombino se infunde al reportaje para comentar una coyuntura histórica que no pudo presenciar, así cuestionando esa distancia entre el saber objetivo y subjetivo que supone la supuesta modernidad. Este espacio le permite pronunciarse sobre la relación entre la violencia colonial, rituales prehispánicos y la subjetividad letrada en la materialización de los procesos históricos de la guerra. Así mismo, se despliegan sus propias contradicciones o limitaciones respecto al presente y el pasado indígena.

Narrado en primera persona, el cuento relata la historia de un periodista que viaja a México, "en una comisión periodística, de una ciudad frontera" $(2011,340)$ con Estados Unidos. Este corresponsal de guerra, a diferencia del resto de los personajes, no tiene nacionalidad; y el lugar de su misión nos remonta a espacios fronterizos, ya no entre Honduras y Nicaragua como el lugar de su primer recuerdo, sino que entre México y Estados Unidos. Además de los sujetos anónimos

26 Se publica en el Diario de Centro-América, 10 de mayo de 1915 durante su corta estadía en el país como invitado de Cabrera Estrada, en su ruta por Nicaragua poco antes de su muerte. El mismo texto se publica en La Nación el 5 de junio de 1914.

27 Para un estudio detallado del cuento, referirse al texto de Mora Valcárcel, 2000, pp. 15-32. Interesante notar que en el año de su estudio la autora señala que no existe una edición definitiva del relato, recalcando otra vez la precariedad del archive de la obra de Darío.

28 De Mora Valcárcel, 2000, p. 16.

29 Para un estudio detallado del cuento, referirse al texto de Mora Valcárcel, 2000, pp. 15-32. La autora señala que no existe una edición definitiva del relato, como lo ejemplifica la última línea del cuento, recalcando otra vez la precariedad del archivo de la obra de Darío. Nappo (2017) también tiene un artículo pertinente titulado "Rubén Darío, lo fantástico y la Revolución Mexicana” en Revista Ístmica, número 20. 
mexicanos, los personajes principales son también viajeros: el Mr. John Perhaps, médico periodista "al servicio de diarios norteamericanos" (2011, p. 340); “ Coronel Reguera, o, mejor dicho, el padre Reguera" (2011, p. 340), un personaje vasco, y el propio narrador nómade. Los nombres caricaturescos apuntan al humor que socava la experiencia individual de los personajes, tanto históricos como ficticios. Con el mismo tono humorístico, le hace un guiño a sus lectores argentinos, haciendo alusiones a su remota patria ${ }^{30}$.

Con estructura cinematográfica el cuento sigue la perspectiva del narrador, enfocando en los diálogos y en la descripción de los personajes y del entorno. La naturaleza interrumpe esta subjetividad letrada cuando Reguera suspende su monólogo para cortar una vara y asustar a una "gran víbora" (Cascabel, 2011, p. 343), precisamente cuando el narrador percibe la ausencia de Mr. Perhaps. Además de aludir a sus múltiples simbolismos, este animal anticipa el ritual alucinado que puntea la historia ${ }^{31}$. Después de ese primer encuentro con el entorno natural se presenta "una gran arboleada tras la cual oíase el ruido del agua de una quebrada", curiosamente "el sitio más delicado que ocupaban las fuerzas revolucionarias" (Cascabel, 2011, p. 343). La encrucijada de resistencia en el ámbito silvestre anticipa la fuente de su último poema, y marca el escenario futuro de las guerras de guerrillas. Explayando su sensibilidad a la biodiversidad autóctona, el siguiente referente natural es un "gran ahuehuete" (Cascabel, 2011, p. 343).

Tras tomar comiteco y fumar marijuana se acentúa su percepción del entorno: "Todo era silencio en la selva, pero silencio temeroso, bajo la luz pálida de la luna [...] Ya conocía esa siniestra música de las selvas salvajes: era el aullido de los coyotes" (Cascabel, 2011, p. 343). El escenario de lo insólito está en la naturaleza, hecho hostil con los efectos narcóticos que producen el valor fantástico del texto. La hierba y el uso de los distintos licores apuntan a otro tentáculo del bio-poder, al que fue sometido Darío por su alcoholismo. Este cuento registra en la ficción el mecanismo químico que distorsiona la percepción y que a su vez auto-sometió a Darío a otra forma de bio-política, relacionada con patrones de consumo y de producción. En la ficción, el narrador, testigo alucinante del rito, busca esconderse

tras un tronco de árbol yo estaba en mi pavoroso silencio. Creí padecer una alucinación; pero lo que en realidad había era aquel gran círculo que formaban esos lobos de América, esos aullantes coyotes más fatídicos que los lobos de Europa. (Cascabel, 2011, p. 344)

30 Prestándose del habla coloquial, Darío hace referencia a Argentina en su caracterización del otro periodista “¡No digas macanas! -contestaba Mister Perhaps, que había estado en Argentina” (2011, p. 340).

31 En el cuento hace referencia a un altar de "Teoyaomiqui, la diosa de la muerte. En aquella piedra se agitaban serpientes vivas,". La estatua de Coatlicue fue equivocadamente identificada como Teoyaomiqui, según la Biblioteca del congreso. https://www.loc.gov/item/2014647495/., probablemente por Don Antonio De León y Gama. Huitzilopochtli y Teoyoamiqui son deidades parejas. 
Con esta metáfora de ferocidad canina representa, por última vez en prosa, la lucha imperial que circunda la realidad histórica transnacional de América. Este recorte casi visual se presta a una caricatura política que ubica a la voz poética en el tronco de un árbol, el ser "casi sensitivo" que figura en su imaginario poético. Podría decirse que, a través de esta última ficción, se plasma un reportaje imaginado de la Revolución Mexicana y de la tensión tradicional entre subjetividad letrada y la naturaleza, como también entre los distintos géneros literarios. Insistiendo en el mundo de las letras, paradójicamente sustentado por ontologías y epistemologías precolombinas, el cuento cierra: "Vino a mi cerebro, como escrito en letras de sangre: Huitilopoxtli"32 (2011, p. 344). Queda inscrito en el material humano, con material biológico, las palabras de este referente mítico de guerra, sacrificio y destrucción.

Los últimos textos en prosa de Darío reflexionan, en parte, sobre la simultaneidad de los mecanismos de bio-poder que experimentó y observó el escritor. La recurrencia del valor de la sangre pasa de lo ritual a lo clínico, de lo colectivo a lo individual, de lo simbólico a lo material, para así subrayar su tragedia. Igualmente, la tiranía se presenta ante la mecanización del cuerpo a través de la regulación/ análisis de la sexualidad, en sus implicaciones literales y figuradas. Retomando el epígrafe, la muerte es el límite del poder, lo más secreto/privado de la existencia, desde la que el escritor expone el arnés bio-político de la modernidad. Todos sus últimos escritos van atravesados por esa primera persona que insiste en el humanismo clásico y en esa privacidad que supone el fin. A pesar de internalizarla y reflejar los mecanismos de esa hegemonía, una lectura de estos textos apunta también a una ontología que esquiva esos paradigmas occidentales. Dejando vislumbrar una subjetividad nómada y trashumante, desde cuyo umbral sortea el cosmopolitismo de su época y el nacionalismo vigente todavía en nuestros días.

\section{Referencias bibliográficas}

Acereda, A. (2012). Nuestro más profundo y sublime secreto: Los amores transgresores entre Rubén Darío y Amado Nervo. Bulletin of Spanish Studies. Vol. 89, No 6: 895-924.

Agambem, G. (2005). Lo abierto: El hombre y el animal. Traducido al español de L'aperto. L'uomo e l'animale. Valencia: Ed. Pretextos.

Blandón, E. (2011). Discursos transversales: la recepción de Rubén Dario en Nicaragua. Managua: Banco Central de Nicaragua.

32 Algunas versiones del cuento no incluyen esta última línea, como explica de Mora Valcárcel, 2000, p. 16. 
Blandón, E. (2010). Rubén Darío: Mutilación y monumentalización. En Browitt, J. y Mackenbach, W. (eds.), Rubén Dario: cosmopolita arraigado (pp. 104-126). Managua: Instituto de Historia de Nicaragua y Centroamérica.

Braidotti, R. (2011). Nomadic subjects: embodiment and sexual difference in contemporary feminist theory. 2a ed. New York: Columbia University Press.

Browitt, J. y Mackenbach, W. (eds.). (2010). 'Respirar el Torbellino de su Capricho' el cosmopolitismo dariano. En Rubén Dario: cosmopolita arraigado, (pp. 1-16). Managua: Instituto de Historia de Nicaragua y Centroamérica.

Contreras, F. (2012). Rubén Darío: Su vida y su obra. Bloomington: iUniverse.

Darío, R. (1977). Poesía. Caracas: Biblioteca Ayacucho.

Darío, R. (1991). La vida de Rubén Darío escrita por el mismo. Caracas: Colección "La Expresión Americana".

Darío, R. (2000). Cartas desconocidas de Rubén Darío: 1882-1916. Managua: Academia Nicaragüense de la lengua.

Darío, R. (2011). Cuentos completos. Buenos Aires: Editorial Losada.

Darío, R. (2013). Viajes de un cosmopolita extremo. Buenos Aires: Fondo de Cultura Económica de Argentina.

Delgado Aburto, L. (2005). La vida de Rubén Dario escrita por el mismo. Escritura autobiográfica y políticas del nombre. Istmo Revista de Estudios Centroamericanos, no 10. Recuperado de http://istmo.denison.edu/n10/ articulos/vida.html

Delgado Aburto, L. (2012). Excéntricos y periféricos: escritura autobiográfica y modernidad en Centroamérica. Pittsburgh: Universidad de Pittsburgh, Instituto Internacional de Literatura Iberoamericana.

DeVries, S. (2013). Green Modernism. En A History of Ecology and Environmentalism in Spanish American Literature, (pp. 99-136). United Kingdom: Bucknell University Press.

Foucault, M. (1990). The History of Sexuality. Vol. 1: An Introduction. New York: Vintage Books Ed.

Gutiérrez, G. R. (1983). Modernismo: supuestos históricos y culturales. México: Fondo Cultural Económica.

Heise, U. K. (2008). Sense of Place and Sense of Planet. New York: Oxford University Press. 
Latour, B. (2013). Políticas de la naturaleza: Por una democracia de las ciencias. Traducción al español del francés. Barcelona: RBA libros.

Library of Congress. (marzo, 2018). Mexico. Aztec Idor Teoyaomiqui Mexico. Aztec Idol Teoyaomiqui, side. Recuperado de https://www.loc.gov/ item/2014647495/

Medina, J. (2010). Retrato de un proceso profano: Rubén Darío y la agonía del poeta moderno. En Browitt J. y Mackenbach, W. (eds.), Rubén Dario: cosmopolita arraigado, (pp. 82-103). Managua: Instituto de Historia de Nicaragua y Centroamérica.

Medina, J. (2005). Vestíbulos del hombre público: Prólogos desconocidos de Rubén Darío. A contracorriente: Una revista de historia Social y literatura de América Latina. Vol. 3 No. 2, Invierno, 127-155.

Montero, Ó. (1998). Modernism and Homophobia. En Balderston, D. y Guy, D.J. (eds), Sex and Sexuality in Latin America, (pp. 101-117), New York: New York University Press.

Mora Valcárcel, C. de. (2000). En breve: estudio sobre el cuento hispanoamericano contemporáneo. Sevilla: Universidad de Sevilla.

Morton, T. (2009). Ecology Without Nature: Rethinking Environmental Aesthetics. Hanover: Harvard University Press.

Nappo. D. J. (2017). Rubén Darío y la Revolución Mexicana. Ístmica. No. 20, 55-67.

Rama, Á. (1985). Rubén Darío y el modernismo. Barcelona: Alfadil Ediciones.

Rama, Á. (1995). La ciudad letrada, prólogo de Hugo Achurar. Montevideo: Arca.

White, S. (2011). Arando el Aire: La ecología en la poesía y la música de Nicaragua. Managua: 400 Elefantes.

White, S. (Enenro, 2011). Written on Earth and Water: Poetry and Ecology in Nicaragua. WorldLiteratureToday.Recuperadodehttp://www.worldliteraturetoday.org/2011/ january/written-earth-and-water-poetry-and-ecology-nicaragua-steven-f-white

Zanetti, S. (2004). Rubén Darío en La Nación de Buenos Aires: 1892-1916. Argentina: Editorial Universitaria de Buenos Aires. 